\title{
Occupational stress and addiction: Possible neuro- biological elucidation of medical waste related individuals
}

\author{
Masum A Patwary ${ }^{1,2}$, Lucina Q. Uddin ${ }^{3}$, M. Abdul J alil Miah ${ }^{4}$, Mosharraf H. Sarker ${ }^{5}$ \\ 1. Geography and Environmental Science, Begum Rokeya University, Rangpur, Bangladesh. 2. School of Science and \\ Engineering, Teesside University, Middlesbrough, United Kingdom. 3. Psychiatry and Behavioural Sciences, Stanford \\ University School of Medicine, Stanford, CA, USA. 4. Begum Rokeya University, Rangpur, Bangladesh. 5. School of Science \\ and Engineering, Teesside University, Middlesbrough, United Kingdom
}

Correspondence: Masum A Patwary. Address: Geography and Environmental Science, Begum Rokeya University Rangpur 5400, Bangladesh. E-mail: patwaryma@gmail.com; M.patwary@tees.ac.uk

Received: September 12, 2012 Accepted: December 2, $2012 \quad$ Online Published: January 4, 2013

DOI : 10.5430/jha.v2n2p71 URL: http://dx.doi.org/10.5430/jha.v2n2p71

\section{Abstract}

Multiple factors contribute to the tendency to develop drug addictions, including social or psychological and occupational stressors. Most studies examining causes of and treatments for drug addiction have been conducted in Western developed nations. Here we used phenomenological research approach to explore the neurobiological explanation of drug addiction and to investigate attitudes towards drug use amongst individuals working with medical waste. Data were collected in Dhaka, the capital of Bangladesh, using a variety of techniques based on formal representative sampling for fixed populations and adaptive sampling for roaming populations. We found that over half of participants interviewed reported using illicit substances to cope with occupational stress. Self-reported disease symptoms related to stress were reported by most of the respondents. Working with horrifying waste contributes to increased stress among the participants. These results indicate that in the case of these workers, workplace stressors along with cultural and socio-economic context uniquely contribute to, and exacerbate, tendencies toward drug addiction.

\section{Key words}

Occupational stress, Drug addiction, Medical waste, Qualitative study, Neurobiology

\section{I ntroduction}

Drug addiction is a complex neurobiological phenomenon in which an individual experiences a compulsive drive to take a drug despite serious adverse consequences. Studies on drug addiction may focus on neurobiology ${ }^{[1,2,3]}$ or on the psychosocial stresses (for example work stress) that may increase the likelihood of drug addiction ${ }^{[4,5]}$.

Current theories of the neurobiology of drug addiction consider the interaction of impairments in brain systems underlying motivation-reward, affect regulation, and behavioural inhibition ${ }^{[1,2,6]}$. Existing empirical work points to potential abnormalities in anterior cingulate gyrus, orbitofrontal cortex, and ventromedial prefrontal cortex, as well as dysregulation of mesolimbic dopamine circuits, contributing to addictive behaviours ${ }^{[1]}$. This neuroscientific work has been conducted in 
developed nations, and very little focus has been directed towards incorporating socio-economic and socio-cultural factors into theories of the neurobiology underlying drug addiction.

The idea that work circumstances can influence drug addiction has been a topic for assumption and debate for centuries. Individuals often point to stress, job or personal pressures, anxiety, depression or other stressful life events as reasons they might have initiated illicit drug use and thus leading toward clinical syndromes of drug addiction ${ }^{[7-9]}$. Margolis and Kroes ${ }^{[10]}$ defined job stress as a circumstance in which some work-related condition or process, or combination of these factors, interacts with the worker to disrupt psychological or physiological homeostasis. Stress effects can be either physiological or psychological (cognitive effects) and these effects can present a mechanism to disturb health and behaviour ${ }^{[11,12]}$. Behavioural disinhibition and behavioural inhibition/anxiety may serve as individual difference pathways for genetic influence on alcohol abuse and dependence ${ }^{[13]}$. Risk factors such as easy access to alcohol (bartending), nights spent away from home (sales, truck driving, sea faring) and boredom have all been considered ${ }^{[14-23]}$.

A common theme among studies of occupational stresses has been the consideration of those that arise when an individual has little control over working conditions ${ }^{[24]}$. Low control coupled with high demands can lead to avoidance and helplessness, in turn diminishing the individual's capacity to find solutions and develop coping strategies ${ }^{\text {[25] }}$. The Demand: Control model has been shown to have predictive value for psychological dysfunctioning and depressive disorders ${ }^{[26]}$, cardiovascular disease and risk factors for cardiovascular disease ${ }^{[27]}$, musculoskeletal disease ${ }^{[28]}$, and pregnancy outcomes ${ }^{[25,29]}$.

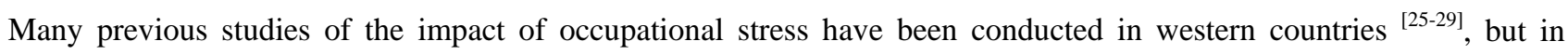
developing countries individuals may suffer different, possibly more extreme, stresses. The present investigation was undertaken in Bangladesh among individuals exposed to medical waste (IEMW) including doctors, nurses, admin staffs, waste collectors, mortuary workers, scavengers and recycle operators. It is recognised that individuals in these groups are subject to significant pressures, whatever their position in the profession, which may result in psychological stress and drug-abuse problems. Western studies have found an inverse relationship between problematic alcohol use and both level of education ${ }^{[30]}$ and socio-economic status ${ }^{[31,32]}$.

The purpose of this phenomenological interpretive study was to gather and consider the views of different medical waste related individuals in Dhaka, Bangladesh where the stresses of working with horrendous and hazardous medical waste are likely to be compounded with the pressures of working environment. Our findings also have elucidations for the neurobiology of addiction, in that they highlight key understudied factors in drug use initiation.

\section{Methodology}

\subsection{Research design}

An interpretive hermeneutic phenomenological research approach ${ }^{[33-37]}$ was adopted in order to provide an understanding of the subject population's beliefs and perceptions. Within this framework, ethnographic data was collected using observation, formal and informal dialogue and third person listening techniques ${ }^{[38-40]}$. Where possible, interviews were formally prearranged, but informal opportunities were also taken, at times and place where the participant's interest could be obtained and retained.

\subsection{Selection of study group}

Initial observation suggested that four significant and distinct groups of people are involved with the handling of medical waste in the study area as follows:

Within healthcare establishment (HCE) the following groups were considered; 
Involved with live patient:

- Senior HCE staff: This group included managers and officials, doctors, nurses and other individuals involved directly in patient care as well as forensic physicians and senior support staff

- Cleaners: This group included waste operatives, in particular individuals transferring waste from HCE inside bins to roadside bins.

Involved with dead body:

- Domes: A distinct group of official and unofficial mortuary assistants involved in opening the body for examination by physicians and suturing the body prior to handing it over to the relatives. On the other hand the group defined by the local term 'dome', was observed to exhibit a significant group identity, sharing a distinctive manner, bearing, and expression. A significant distinction was the behaviour and attitudes. This finding is also supported by Patwary et al. ${ }^{[35]}$ The group can be considered to consist of: (a) official domes, recruited and paid by the hospital; and (b) unofficial domes, generally relatives of the official domes, receiving payment from relatives of the deceased in return for help in dealing with the body. In the Asian sub-continent these groups tend to be drawn from poor or disadvantaged communities. They may be known as dalits (literally: downtrodden, crushed) or by other names such as Asprsya, Achut, Chandala, Harijan, Scheduled Caste, or Untouchable ${ }^{[41]}$.

Outside the HCE, others exposed to medical waste were included in the study. These included:

- Scavengers involved in unauthorised scavenging and resale of medical waste. Many individuals were observed to be involved in general waste scavenging, but a smaller group was found to specialise in medical waste scavenging. It is this smaller group that was chosen for the current study.

- Individuals involved in informal recycling and repacking of medical waste.

\subsection{Determination of Sample Size}

Having identified these potentially significant groups, each group was sampled according to a sampling plan appropriate to that type of population. Sample size refers to the number of subjects to be included in the study. These were sampled according to 95\% confidence intervals using a Population Proportionate to Size (PPS) stratified plan ${ }^{[42-45]}$ considering four study subjects. This suggested a sample size of 256. The sample size was allocated to different categories on a PPS basis, with redistribution of the sample to ensure that the minimum sample size required for any group was $20^{[44]}$.

Table 1. Allocation of the sample population size in the studied HCEs

\begin{tabular}{lll}
\hline HCE & Total Population & Allocation of sample (PPS) \\
\hline Hospital & 318 & 95 \\
Clinic & 152 & 46 \\
Pathology/diagnostic centre & 166 & 50 \\
Total & 636 & 191 \\
\hline
\end{tabular}

HCE: Healthcare Establishment; PPS: Popn proportionate to size

Group one: HCE employees; A representative sample of HCEs (69) were considered as described in Patwary et al. ${ }^{[45,46] \text {, }}$ where three types of HCEs were considered; hospitals $(n=4)$, clinics $(n=21)$ and diagnostic centres $(n=44)$. It was found that a total of 636 individuals are currently employed by the different HCEs considered in this study. The final sample size of the target participants were found to be $n=191$ (Table 1). The sample size was allocated in different categories of HCE 
on a population proportionate to size basis, where the number of respondents selected from hospitals was $n=95$, from clinics $n=46$ and from pathology/diagnostic centres $n=50$.

Group two: Domes; The total population of this small group was found to be $n=23$ employees. Twenty participants of this group were selected by using a purposive/authoritative sampling technique based on the sample size mentioned before.

Group three: Scavengers; A further significant group (those involved in a grey or black economy of scavenging, recycling and reselling) was also identified. An "adaptive sampling for roaming population” ${ }^{[47,48]}$ approach was adopted to study this group. The technique allows the sampling design to be adapted based on observations made during the survey, and has been found to be useful when the population of interest is irregular, hidden or hard to reach, and may provide the only practical way to obtain a sample which is large enough for the study objectives ${ }^{[49,50]}$. Using this approach, the number of people involved with this activity was estimated $(n=75)$, and the structure of the group was observed. Having established an outline structure for the group in this way, it was possible to select a sample of $(n=25)$ participants, using a link-tracing design, as described in Thompson and Frank ${ }^{[48]}$, to find sufficient participants who were able and willing to give informed consent. It must be recognised that many were not willing or able to give consent, and that the sample may not be completely representative of the general group.

Group four: Re-packagers and Recyclers; The total population of this group was estimated by a 'reconnaissance survey' to be 53 individuals, and $n=20$ sample representatives were selected and interviewed following a combination of the formal and informal approach as judged appropriate in each individual circumstance.

Each participant was given a unique code number (Rs1- Rs259) which was recorded along with sex and age. Data were collected during the period of February 2006 to January 2010.

\subsection{Ethical considerations}

This study was approved by the Ethics Committee of the Teesside University. Permission to conduct the research was obtained from each management of the HCEs, Director General of Health, Government of Bangladesh, recycle industries and consent was obtained from each of the individual participants. Participation was voluntary with informed consent. The research methodology was designed to avoid deception and physical and/or emotional harm to the participants. Confidentiality, data security, and safety for respondents were assured. Research was conducted verbally in the local language Bangla (Bengali). Respondents’ original names have been changed by the alternative in the study.

\subsection{Data collection}

\subsubsection{Observational approach}

An observational approach reduces the impact of the data collection process on the behaviours of the observed population ${ }^{[51]}$. The investigator watched the actions and behaviours of selected participants in their usual settings, noting the routine aspects of daily life and nature of work activities ${ }^{[52]}$.

\subsubsection{Third Person Listening Approach}

A third person listening approach was used to develop an understanding of the interaction between two or more individuals within the pragmatic social and cultural environment of their workplace as described by Patwary et al. ${ }^{[35,36]}$ In this listening approach, the researcher concentrated on the interactions between two or more speakers and, as well as noting key aspects of the conversation, observed other signals such as fleeting facial expressions, how the tone of voice shifted, and body language accumulated as unfocused impressions ${ }^{[53]}$ and in later stages, more focused data ${ }^{[54]}$. 


\subsubsection{Formal interview}

A number of formal structured interviews were arranged, as judged appropriate in each individual circumstance, including demographic information, occupational activity, questions dealing with sick leave, medication, use of medicine and finally stress related to work, coping strategies, smoking habits, alcohol consumption and illicit drug use.

\subsubsection{I nformal dialogue}

An informal dialogue approach was used where formal techniques were not judged appropriate. The dialogue approach involved face-to-face interviews between the researcher and selected informants at times and places where the participant's interest could be obtained and retained. Interviews were conducted in tea-stalls or in a local restaurant, close to a roadside or in a road, at any free time, during the day or at night, in good weather or bad. Although no formal structure was possible in these circumstances, the areas of questioning were the same as those described for formal interviews.

\subsubsection{Focus group discussion}

One focus group discussion (FGD) was conducted with volunteers from each of the various subject groups, the categories of the group members in each group were FG-1 (HCE senior management and owners, doctors, nurses); FG-2 (HCEs waste operatives); FG-3 (Treatment operatives); FG-4 (Scavengers); FG-5 (Recycle operatives) and a special FG-6 (Only for mortuary workers 'domes'). Focus group methodology was adopted to collect qualitative descriptive data to identify and explore the attitudes and beliefs about occupational stress and circumstances. Data for this study came directly from the information provided by participants within six focus groups. These focus groups explored attitudes, beliefs, and social/cultural norms and values in a group-discussion format. This group setting provided a forum that encouraged the participants with depression to disclose their personal experiences with depression, to reveal their attitudes and beliefs concerning cognitive behaviour, and to brainstorm about strategies to cope with daily working activities. The focus groups were audio-recorded and subsequently transcribed by a professional transcript writer and checked for accuracy.

\subsubsection{Setting and participants}

General beliefs about depression related to occupational stress were extracted with several open-ended questions. Examples of questions asked were: “When and why do you feel work related depression or stress?" "What do you think causes this stress?” The focus of the group discussion and informal dialogue approach progressed by asking more specific questions about their personal experiences with the daily stressful circumstance: "How do you know when you are stressed?" "How has stress affected you in the work environment?" "How has it affected your daily life?” and then began to target how participants chose to manage their stress: "How do you usually cope with stress?" "What strategy preferences do you have in coping with work related stress?" "What experiences have you had seeking strategies for coping with stress?” Understanding how social and cultural stratification impacted their beliefs and attitudes about their working environment was also critically important. Therefore, a question concerning their beliefs about social and cultural stratification and working positions (excluding senior officials) was also asked: "How do the experiences of your working environment as a lower class employee contribute to stress in your daily life?” Probes were utilized by the facilitator to gain a deeper understanding into individual responses. The results were analysed by pseudo-scoring method and presented in the table 4 in result section.

\subsubsection{Data analysis}

Data analysis was conducted by using six activities for conducting hermeneutic phenomenological research as described by van Manen ${ }^{[54,55]}$ and Brysiewicz ${ }^{[34]}$. Hermeneutic phenomenology was chosen for its ease of interpretation. Hermeneutic phenomenological research approach ${ }^{[34,54,55]}$ was adopted in order to provide an understanding of study subjects beliefs and perceptions. The term "hermeneutics”, a Greek origin ('hermeneuo' translated to 'interpret' [56] , which is philosophical in nature, can be used as the theory and practice of interpretation and understanding ${ }^{[57]}$. It is a "research 
methodology aimed at producing rich textual descriptions of the experiencing of selected phenomena in the lifeworld of individuals that are able to connect with the experience of all of us collectively" ${ }^{\text {[34] }}$ Communication and language are intertwined where hermeneutics offers a way of understanding such experiences portrayed through language and in

context ${ }^{[34]}$. The six activities for conducting hermeneutic phenomenological research as described by Manen ${ }^{[35,34]}$ and Brysiewicz ${ }^{[34]}$ are as follows:

- Nature of lived experience; attempted to make sense of the phenomenon through deep thought and questioning regarding the participants' experiences;

- Investigating the experience and reflecting on the emerging themes;

- A question about what it is that gives the experience its special significance;

- Describing the phenomenon in writing and bringing the experience "into speech";

- To understand the phenomenon in a full and human sense; to maintain a relationship with the phenomenon of interest;

- Putting everything together by stepping back and attempting to look at the complete picture of the phenomenon.

Finally, these were combined in a grounded theory approach following Glaser and Strauss ${ }^{[58]}$. Manual line-by-line in-vivo microanalysis ${ }^{[37]}$ of the interview data was conducted. Each line of text was read and assigned a code utilizing the respondents' own words. The researchers examined the interview narratives and field notes looking for indications of categories. With each category, it was coded on the document, and after several read-throughs, the codes developed into a name that described the event or issue. Each code was then transferred into a separate document in which consistent categories could be again compared. For example, when respondents expressed their views about "nature of the work leading to stress", the instance would be labelled "work environment and stress," and the content would be transferred to the "work environment and stress" document. Subcategories were constructed when needed. Categories of data were then combined to create over-arching themes. This process was repeated several times, as the codes had to be re-organized and re-named after further comparisons with other events. Once the categories became more firm, the core themes became the central focus of the research. The results section of this manuscript was developed based on the categories of central focus. The chosen methods acknowledge the complexity of the interactions between and within the different groups of participants and their interactions with the surrounding environment and the general population.

Self-reported disease signs and symptoms presented by the individual at least once in the last week or twice in the previous 3 months were recorded prior to the date on when the questionnaire was completed. However, persons with a known previous history of asthma, cardiac problems or under medication for any ailments were excluded from this study. Since many respondents were illiterate or poorly educated, the investigators explained the health related questions. Self-reported disease symptoms were scored by using the pseudo-score system ${ }^{[59]}$. This system was chosen for its ease of interpretation. The respondents were asked to prioritize symptoms which affected them and to rank disease symptoms according to priority. After that, Chi-square $\left(x^{2}\right)$ test was performed to analyse the significance of the symptoms among the subjects. Structured questionnaire data were recorded in SPSS for analysis by descriptive statistical methods.

\section{Results and findings}

\subsection{Demographic information}

The educational characteristics of the sampled populations are presented in Table 2. Most of the HCE workers (96\%) were found to be literate because of the job recruitment policy. Only $4 \%$ were illiterate, and the survey revealed that they were recruited on an emergency basis by the HCE authorities. Although dome and scavenging is thought to be undertaken by 
"untouchable" marginalized populations in society, in the present study all scavengers were found to be literate and most of them studied at the school level or above.

Table 2. Educational characteristics of the study subjects

\begin{tabular}{lllll}
\hline Occupation & $\begin{array}{l}\text { Group One: } \\
\text { *HCEs employees (\%) }\end{array}$ & $\begin{array}{l}\text { Group Two: } \\
\text { Dome (\%) }\end{array}$ & $\begin{array}{l}\text { Group Three: } \\
\text { Scavengers (\%) }\end{array}$ & $\begin{array}{l}\text { Group four: recycle } \\
\text { operator (\%) }\end{array}$ \\
\hline Illiterate & $8(4.18)$ & 0 & 0 & 0 \\
Primary & $24(12.56)$ & $15(66)$ & $14(56)$ & $14(70)$ \\
Secondary & $127(66.49)$ & $5(21)$ & $10(40)$ & $5(25)$ \\
College & $27(14.13)$ & $3(13)$ & $1(4)$ & $1(5)$ \\
Above college & $5(2.61)$ & 0 & 0 & 0 \\
Total & 191 & 23 & 25 & 20 \\
\hline
\end{tabular}

*Doctors, nurses, waste operatives

\subsection{Self-reported disease symptoms}

The prevalence of self-reported respiratory and upper chest related symptoms such as dry cough, cough with phlegm, wheezing, shortness of breath, breathlessness and chest tightness were found to differ among the different study subjects (Figure 1). Dry cough was reported to be high in HCE employees and scavengers. Cough with phlegm was observed as higher in treatment workers and recycling operators. A similar result was observed by Nielsen et al. ${ }^{[60]}$ in his study in Denmark among the group of street cleaners on their self-reported symptoms which included coughing, phlegm, and chronic bronchitis. The prevalence of self-reported clinical symptoms headache, dizziness, difficulties of concentration, loss of appetite and vomiting related to stress were reported to be high among the respondents of the sampled subject groups.

Figure 1. Self-reported respiratory and upper chest related symptoms among the study

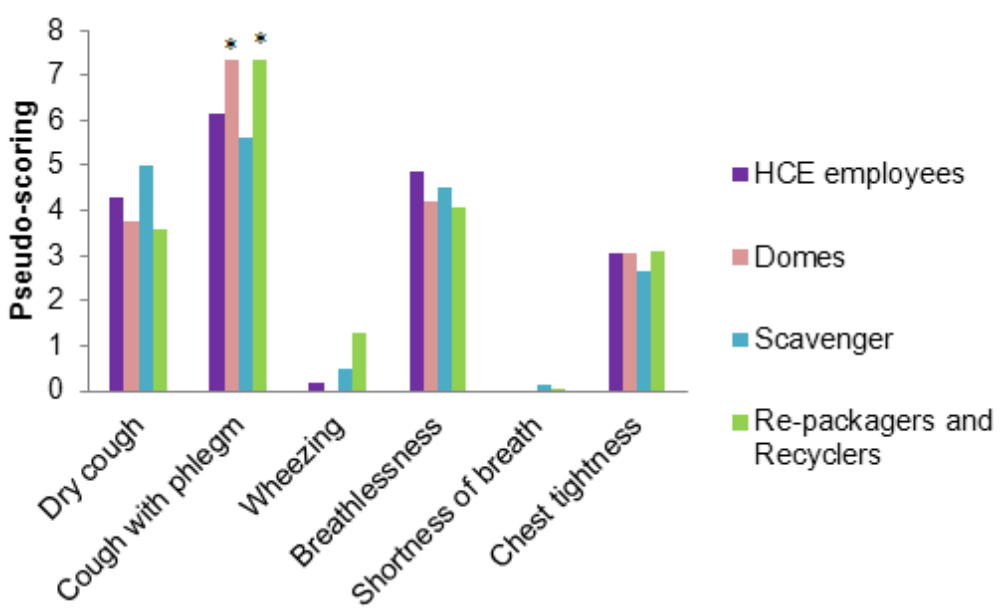
subjects

The prevalence of self-reported stress related symptoms such as headache, heaviness of head, occupational stress, dizziness, tiredness and concentration difficulties were found to differ among the different study subjects (Figure 2). Most of the stress related symptoms were reported to be significantly higher amongst the HCE employees, scavengers and re-packagers \& recyclers than the subject group dome while concentration difficulties were observed to be significantly higher in domes than other subjects. Patwary et al., ${ }^{[35]}$ described one of the major reasons of hereditary occupation 'dome' as they resort to alcohol even in the official restrictions. It could be assumed that they cannot feel their stress as they are 
all-time in alcohol addiction. Similarly they have less concentration in their work as they are always in addiction. In addition Occupational stress is more or less similar among the three subject groups except dome.

Figure 2. Self-reported disease symptoms related to stress among the subjects

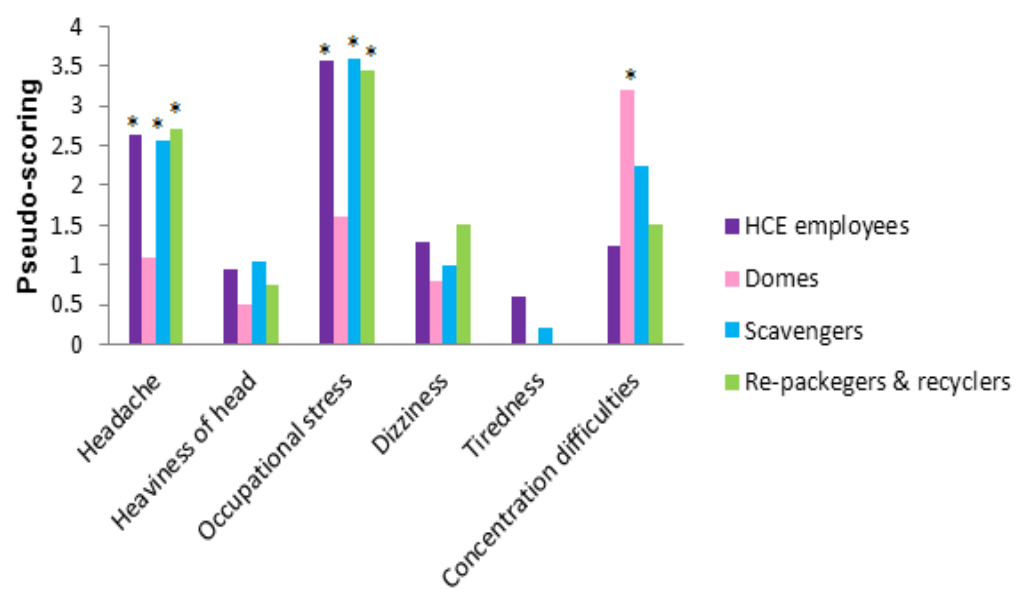

\subsection{Substances used}

The prevalence of different illicit alcohol and drug users within the sampled populations are presented in Table 3. Nearly half of the subject sampled (43\%) were found to be illicit alcohol and drug users. They reported use of Ganja (Marijuana), Puria (Heroin), Da-ill (Phyncidile), Cocaine, Ecstasy, Yaba, and Crystal Meth. Among the illicit drug users (43\% of the total sampled population), 35\% resorted only to alcohol, 28\% were injecting drug users only, $20 \%$ were both injecting drug users and alcohol users, and 17\% were users of various types of drugs. Most of the respondents reported that the use of the drug depended on the ease of access to the drug. Many of the HCE operatives reported stealing sedative painkillers, including morphine and sleeping pills meant for patients. Doctors, nurses and a number of officials were also used to either drugs or alcohols. All of the respondents from both the domes and scavengers groups reported that they were illicit alcohol and drug users. This was supported by observational study as well.

Table 3. The prevalence of the illicit alcohol and drug use tendency

\begin{tabular}{lllll}
\hline Occupation & $\begin{array}{l}\text { Group One: } \\
\text { *HCEs employees (\%) }\end{array}$ & $\begin{array}{l}\text { Group Two: } \\
\text { Domes (\%) }\end{array}$ & $\begin{array}{l}\text { Group Three: } \\
\text { Scavengers (\%) }\end{array}$ & $\begin{array}{l}\text { Group four: } \\
\text { Recycle operator (\%) }\end{array}$ \\
\hline Non-user & $98(51)$ & 0 & 0 & $13(65)$ \\
Occasionally & $45(24)$ & 0 & 0 & $2(10)$ \\
Regularly & $20(10)$ & $14(61)$ & $10(40)$ & $2(10)$ \\
Addicted & $28(15)$ & $9(39)$ & $15(60)$ & $3(15)$ \\
Total & 191 & 23 & 25 & 20 \\
\hline
\end{tabular}

*Doctors, nurses, waste operatives.

\subsection{Qualitative findings}

Responses and comments that came from the qualitative discussions fit within the framework of some overarching themes:

a) Attitudes toward working environment and perception of stress

b) Experience of working environment that contributes to stress

c) Beliefs about stress 
d) Self-improvised coping strategies (mostly self-medication).

\subsubsection{Perceptions of stress}

The level of stress observed varied amongst the participants but, when asked "How do you know when you are stressed?", respondents commonly reported the clinical symptoms of stress including: 'sadness'; 'not interested in doing any work'; 'weight loss'; 'insomnia'; 'being tired due to nausea'; 'palpitation'; 'headache'; 'losing concentration'; 'irritability' and 'loss of appetite'. Many (76\%) participants reported other physical symptoms such as 'dizziness'; 'acidity' and 'vomiting'. These qualitative perceptions of stress were also reflected among the self-reported disease symptoms (Figure 2).

The study focussed on individuals involved with medical waste generation such as doctors nurses, including waste collection in HCEs and other places, waste storage, scavenging, waste segregation, waste dumping or disposal, waste cleaning, recycling, repacking and reselling and, when explaining their understanding of stress, each of the participants suggested that they experienced stress due to their work, often mentioning their involvement with hazardous or horrifying medical waste and horrifying working circumstances. They described psychological stress associated with visual sensitivity (Table 4). Further discussion with participants led to the emergence of "Coping with stress" as a linked theme and, finally on further in-depth probing, the key theme of "addictive behaviour" emerged.

Table 4. Occupational stress according to priority in Likert scale through Pseudo-scoring.

\begin{tabular}{lllll}
\hline Occupation & $\begin{array}{l}\text { Group One: } \\
\text { *HCEs employees } \\
(\%)\end{array}$ & $\begin{array}{l}\text { Group Two: } \\
\text { Domes (\%) }\end{array}$ & $\begin{array}{l}\text { Group Three: } \\
\text { Scavengers (\%) }\end{array}$ & $\begin{array}{l}\text { Group four: } \\
\text { Recycle operator } \\
\text { (\%) }\end{array}$ \\
\hline Strongly agree & $36(19)$ & $9(40)$ & $11(44)$ & $9(45)$ \\
Agree & $54(28)$ & $7(30)$ & $9(36)$ & $6(30)$ \\
Neither agree nor disagree & $41(22)$ & $3(13)$ & $3(12)$ & $4(20)$ \\
Disagree & $39(20)$ & $4(17)$ & $1(4)$ & 0 \\
Strongly disagree & $21(11)$ & 0 & $1(4)$ & $1(5)$ \\
Total & 191 & 23 & 25 & 20 \\
\hline
\end{tabular}

*Doctors, nurses, waste operatives.

To help the readers to understand the various themes better, direct quotes are used for illustration as findings from qualitative data. The translation into English is intended to reflect the style of Bengali speech and to capture how the original would sound in English, so expressions that would be considered errors in Bengali have been translated directly without correction (indicated by sic). The translation was undertaken by first author (MP) and independently confirmed by other (MS). Further confirmation of fidelity of translation for quotes chosen for publication was undertaken by an independent verifier (see acknowledgments). Analyses were done in both languages.

\subsubsection{Risk factors}

With the emergence of addictive behaviour as a key theme, the interviews were re-examined to evaluate the risk factors such as demand/control, access and motivations.

\subsubsection{High Demand}

Comments from participants from all groups suggested that the demanding experiences of the work environment led to stress. Participants also drew attention to their use of drugs to deal with this stress. The examples below are typical:

\section{HCE employees}

Doctor and nurse: Occupational stress due to the nature of medical waste was encountered by HCE employees even at a relatively senior level. A senior official Moyeen [Male, aged 44] reported that “...the first day I walked into the patient 
ward I had no idea how I would react. The smell and discarded waste with blood made me a little dizzy; I feel stress to work with it. Therefore I take alcohol to forget this scenario and now I am alcoholic.” Shawpan' a doctor [Male, aged 48] was one of those that described very distressing psychological symptoms, saying that he thought of body parts and blood every moment, even in sleep. He spoke of, “...dreams about blood and cutting body part....brutal body parts walking around me." He had turned to drug taking as self-medication to address these symptoms: "Therefore [then] I take sedatives every night before sleep. Now I am addicted." Mohshina, a senior nurse [Male, Aged 35] was one of many who explained her perception of job-related stress, "we often seeing medical waste stained with blood and anatomical parts. Sometimes it's not easy for us to bear. Therefore, some of us take alcohol, marijuana or phyncidile to forget this scenario and me as well".

Waste operatives: HCE waste operative Shaju (Male, aged 28) also reported occupational stress "I have been working in this hospital since the last two years. It's not so enjoyable... (sic) I have to see human body parts and blood every day. Therefore, I take drug to avoid this from my mind." Shunil's story reveals the stress felt by seeing blood and dead bodies during his early experiences working with medical waste, "... a few days after I started here, I was engaged to move a body part stained with blood from one place to another, it was very difficult for me to accept that situation. One of my colleague suggested if I take some drug I can forget and do this work as usual and then I started to take drug."

Dome: From the dome group, Ujjol [Male, aged 41] indicated that “...without alcohol, we couldn't manage to do this job (which he described as 'inhuman') properly.

Scavenger and recycle operative: Individuals exposed to medical waste outside the HCE also felt stress. From the scavenger group, Moktar [Male, aged 38] claimed "...we are handling waste stained with blood, body fluids and decomposed body parts. Without drugs we can't do this work” while the recycle operative Sujon [Male, aged 29] said, "...we have to clean and wash this waste stained with blood by hand manually. Sometimes it is very difficult while very bad odour comes from this... to avoid this odour many of us, like me, take drugs”.

\subsubsection{Low control}

HCE employees, doctors, nurses: Zahanara [Female, aged 35] a nurse reflected on the history of those person that have died and linked this to her own life, “...their faces are ice-covered in a look of death. Sometimes it was found to be quite eerie and try to say something (sic); I can feel their emotions. It is hard to not look at the deceased's and wonder about who these people were...(sic) did they die with misgivings? I can't avoid this scenario as I am doing this job. I have to watch this type of scenario so many times in my life due to my profession. So that I took some sedatives at the beginning, and now I am addicted."

Majhar [Male, aged 33] another colleague of the previous respondent added with this situation illustrated, “...these things we can't and will never know (sic), but when I am standing next to a stiff deceased, and I am peer down into the lifeless face, I can't help but wonder ...am I ready for my own ending by death. I can't control my emotion. I don't want to remember any of those. But it does. One of colleague suggested me to forget that by taking drugs... and now I am ... (sic).

Social stratification: Many of the most stressed participants were from the dalit group. Many of these individuals believed that they were engaged in this occupation with horrifying medical waste, or as domes, due to limitations placed on them by their social position. This social stratification also seemed to be linked to drug use and involvement with black market activities. Many of the participants from this group admitted involvement with the black market, explaining that this was due to social marginalization and employment constraints. They complained that they were not allowed to go to school or to obtain other jobs. They believed that others think of them as the symbol of impurity, misfortune and a curse to humanity and that this discrimination was being passed on to the next generation. Most of the dalit group reported that, due to the humiliation they experienced there, their children did not like to go school, preferring to 'live like vagabonds'. They 
believed that this led to involvement with drug sellers and the black market and exclusion from any legitimate job opportunity other than joining their parents in the 'traditional' occupations such as domes, waste collectors, and sweepers. Thus it seems as though a lack of control within the legitimate workplace is being passed from generation to generation.

The stories below are typical. For example;

HCE Waste operatives: Rajib [Male, aged 38] said that the waste collectors and sweepers have been engaged in these professions due to birth and family tradition while he added: ".......but it is our fate that modern society called us as 'uncultured' [literally in Bengali; oshamajik] and 'uncivilized' [literally in Bengali; oshovvo]." Some of them were not worried about their present position and drug use, as Mukim explains, "The way we are...we are. It is not a matter of right or wrong. It is their (society) problem that they cannot accept us.” Alam [Male, aged 45] agreed with Komol, “...if we don't get good job we have to engage in any kind of job whether it is risky or horrifying. After starting this job, day by day I lose my concentration (sic)... drug use is the best way to adapt myself in this occupation. Since ... then I have been doing this work, managing money and getting drugs easily."

Dome: Komol [Male, aged 31] from the dalit group told of how he had attended many interviews without success, but got his job as a mortuary assistant without an interview. He explained his luck, whispering “...this is my fate that I have to be a mortuary worker". He went on “... I tried to get a good job, but unfortunately I couldn't manage, and I had been struggling to live with my family members. I had no alternative options. Therefore I choose this profession”. He also added, "Since my childhood, I knew that this profession is related to drug or alcohol and I am also used to... (sic)."

'Shunil' [Male, aged 28] a dome, also from the dalit group, told a frustrating story about involvement with drug use and dealing: “...I am educated and applied for jobs in different departments, but [I was] refused by the authority as I am from lower caste dome family. They rejected me with discourtesy [saying] that I have to work as a dome or at best sweeper. It makes me feel very bad and I realised that this is my fate. I tend to think I am useless (sic)...therefore I think drug use is the best way to forget this matter."

Scavenger and recycle operative: Mukim [Male, aged 37] felt he had faced discrimination: "........we are discriminated in every step of our lives even by the government". He added angrily ".........unfortunately nothing is equal in our daily life from our baby born to any death. This is likely stress in our life. We try to forget this stress every time by taking alcohol, marijuana, phyncidile and others." He included his voice whispering, "I am what I am from the day (sic) I came out from my mother's womb. There was nothing to do about it, but to accept it". Shamol [Male, aged 36] added his voice finally explained his addictive behaviour, "we are in stress [due to] discrimination and moreover we are working with horrible and infectious waste which gives more stress. Therefore we are using alcohol and other drugs to forget this stress."

Studies in the Asian sub-continent have reported alcohol abuse amongst members of lower castes associated with fewer prohibitions against alcohol use compared with individuals from higher castes.

\subsubsection{Access to drugs}

Many of the study subjects such as HCE employees, doctors, nurses, waste collectors, domes, scavengers and recycle operatives reported that they had relatively easy access to the drugs that they used to help them avoid their work-related stress.

HCE employees, doctors and nurses: The first study group feels that they are to some extent overlooked by the authorities due to their positions. HCE employees (officials, doctors, nurses) have access to drugs intended for patients. Hafiz [Male, aged 34] a doctor of many said, “...who will ask me (sic), I can use anything from the hospital”. This was echoed by the subjects of this group. 
Domes: Some users from the marginalised groups feel that they are to some extent overlooked by the authorities due to their positions as dalit, domes or scavengers outside society. For example, even though alcohol use is strictly restricted by the government, some participants felt safe from those restrictions as there is an apparent immunity from the normal restrictions placed on alcohol consumption in Bangladesh among these groups ${ }^{[35]}$. They believe that their occupation is related to drug and alcohol addiction. Debu (Male, aged 22) a young dome willingly explained why he is addicted, "I am a dome, so I have to do this, otherwise my profession would not be skilled (sic)".

Scavengers and recycle operatives: Scavengers and recycle operatives use expired medicines that they find in medical waste. Shajal [Male, aged 38] who explained how these scavenged medicines are used “...the most preferred way is having it like heroin... place the tablet on aluminium foil and heat it from below. We smoke the vapours that rise after the pills are melted". Shankor [Male, aged 34] added his voice finally explained the easy access of drug, "where I am working now this the best way to get various types of medicines (means sedatives, sleeping pills, drowsy pills, mixed syrups etc.), I am doing work with horrifying materials and I am getting my solutions (drugs and expired medicines as a drug) easily from the same work.”

\section{Discussion}

Most current models of the neurobiology of drug addiction posit that the addictive process can be understood as resulting from impairments in motivation-reward, affect regulation, and behavioural inhibition systems ${ }^{[2]}$. In the past, individuals with drug addictions were considered to have voluntarily made poor choices, leading to their addiction. More recent studies show that repeated drug use leads to long-lasting changes in brain structure and function that undermine voluntary control. One of the brain regions most consistently shown to be altered in individuals with drug addictions is the orbitofrontal cortex, which is involved in inhibitory control and compulsive behaviours. It is believed that drugs of addiction alter dopaminergic systems in the brain, making an individual less sensitive to the dopamine that is produced by natural reinforcers ${ }^{[61-63]}$. Over time, cocaine addition, for example, leads to reductions in dopamine receptors and metabolism in the orbitofrontal cortex, and subsequent problems with compulsivity and control ${ }^{[1]}$.

Figure 3. Neurobiology of addiction related

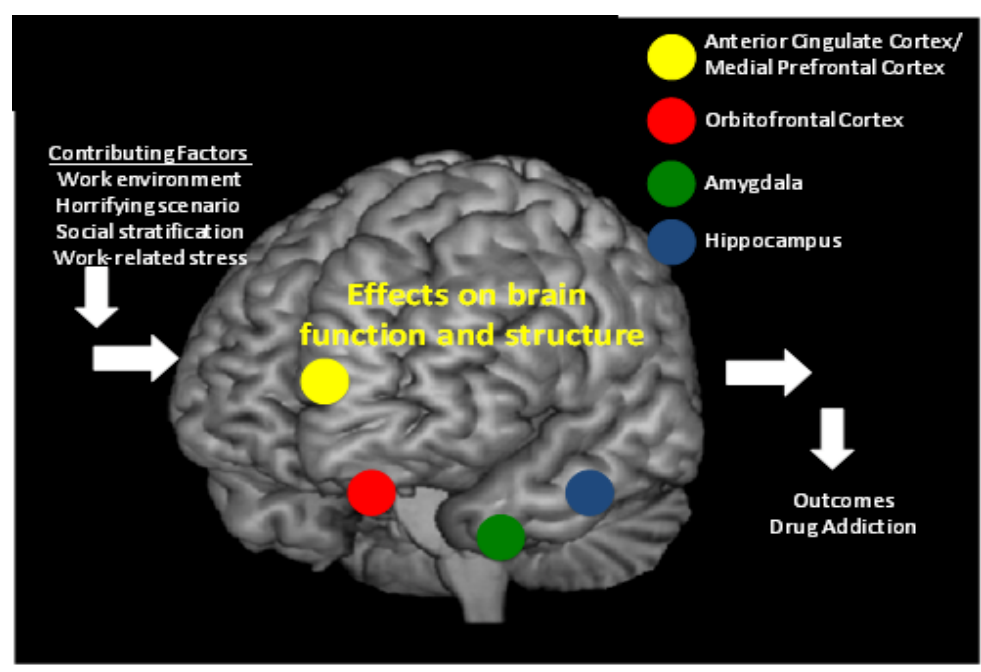
to occupational stress

In addition to affecting brain systems involved in reward and inhibitory control, addiction is thought to be a disease of pathological learning and memory ${ }^{[2]}$. It has been proposed that in drug addiction, neurobiological mechanisms of learning and memory become corrupted by the drugs of abuse, leading to maladaptive associative learning to drug-related stimuli, which have become more powerfully motivating than other biologically relevant stimuli. The "overlearning" of 
drug-acquisition behaviors may play a role in the initiation of the addiction cycle and enhanced vulnerability to relapse by cue-induced environmental ${ }^{[64]}$.

Present study shows research on the neurobiology of addictive behavior has implicated abnormalities in the following brain regions that may contribute to such behaviors: anterior cingulate and medial prefrontal cortex, orbitofrontal cortex, amygdala, and hippocampus. Our research suggests that a number of contributing factors such as social stratification, family fluidity, fatalistic beliefs and job environment may combine work-related stress, with neural vulnerabilities in the above-mentioned brain regions to produce drug addiction and addictive behavior in the individuals studied (Figure 3).

In summary, the neurobiology of drug addiction involves at least four pathways, a) the primary reinforcing effects of drugs of abuse and initiation of neoplastic changes associated with memory formation in the mesolimbic dopaminergic pathway, b) memory consolidation associated with conditioned learning of drug-related stimuli (involving the amygdala and hippocampus), c) motivation, drive, regulation of emotional responses, and salience attribution of environmental stimuli in the orbitofrontal cortex, and d) cognitive and executive inhibitory control functions of the prefrontal cortex and anterior cingulate cortex ${ }^{[64]}$. The stimuli mechanisms of mentioned stress can be similar as well as stimuli mechanisms for addiction.

The demand/control model of occupational stress was developed in western societies. The unique circumstances faced by medical waste workers, particularly in developing countries, exacerbate the likelihood of drug use initiation and addiction in these individuals. Individuals exposed to medical waste in a developing country appear to be subject to unusually extreme job stresses arising from demand and risk. These are largely associated with the horrifying nature of the waste. Superimposed on these already considerable stresses, additional stresses were placed on some participants due to exceptional restrictions on control arising from social stratification ${ }^{[65]}$. This appeared to be linked to fatalistic beliefs. Further risk factors were identified as many participants were able to access drugs and alcohol, either due to their position as excluded groups removed to some extent from normal government controls (in some cases linked to an associations with the black market) or by scavenging (or stealing) medicines from medical waste or directly from HCEs. Due to their position in society, workers from excluded groups face fewer social constraints and thus experience less motivation to resist drug use. Likewise, their fatalistic world view contributes to a lack of motivation for controlling or curbing drug use, which they feel is a necessary coping mechanism. Thus, programs designed to prevent or treat drug addiction amongst these medical waste workers must move beyond pharmacological treatments, and consider the broader psychological and Socio-cultural contexts within which addiction occurs.

Psychological factors may include the urge to drink alcohol to reduce anxiety or symptoms of mental illness and the desire to avoid stress in work circumstances. Individuals working in circumstances that mainstream society would consider horrifying can be seen as 'less than human' ${ }^{[66]}$ or on the edge of society ${ }^{[67]}$. They may suffer from work-related physiological and psychological disturbances and may adopt psychological beliefs relating to the relationship between themselves and the horrifying waste in order to cope ${ }^{[68]}$.

Socio-cultural factors include the availability of drugs and alcoholic beverages alongside an excessively stressful lifestyle. The study revealed that, among some groups, social attitudes were supportive of drug usage, with many participants mentioning advice they had received from their peers recommending alcohol or drugs as a form of self-medication to deal with stress. There was also a sense among the excluded groups that there was a fatalistic acceptance of drug use an inevitable consequence of the position into which they had been born. All of these factors contribute to drug use initiation and continued addiction, and must be incorporated into future models wishing to capture the complex neurobiology of addiction.

This study is the first to apply ethnographic representation and hermeneutic phenomenological analysis to explain drug addiction related to occupational stress through theoretical suggestion of neurobiology. A review of the literature suggests 
that the occupational stress cause of working circumstances related to drug addiction through neurobiological phenomena has not previously been observed. It, too, may have significance to further research by neurobiologists. Detailed neurobiological analysis may find out the result whether this hypothesis is pragmatic or not. To consider the health risks related to occupation stress, it is necessary to identify the potential neurobiological explanation of drug addiction.

Our research suggests that a number of contributing factors such as social stratification, fatalistic beliefs and job environment may combine with work-related occupational stress to produce drug addiction and addictive behavior in the individuals studied. Typically, interventions to treat drug addiction involve pharmacological and behavioural interventions. In the case of the subject individuals described in the current study, tailored interventions that take into account the unique social context in which these individuals work will likely prove most effective.

Limitations: Particular methods (sampling strategies, data collection, data analysis and interpretation) of occupational stress assessment from different perspectives were adopted and described in each particular section. The sampling strategy was mainly probability sampling, which is quantifiable and representative in each particular sample population. Thus, the result could be generalized in each particular perspective as well as generalized as a whole concept. The main reason for the use of multiple representative sampling strategies was to collect the relevant data from different study subjects' so that results could be generalized. However, the conduct of one sampling strategy may not represent the original scenario and could not possibly be as generalizable as the ones in studies like this.

The adopted methodology was multiple sources of data gathering, accumulation and analysis procedures that are simple and easy to access. The assessment of occupational stress can be pooled on a single point with statistical significance. In spite of limitations in accuracy and completeness, multiple sources of collected data through representative sampling methods are relatively easy to obtain and are less likely to reflect bias. The methodology is open to future developments, such as the use of even smaller units (individual level), through improvements in sampling statistics.

The sample frame of the respondents was representative through probability sampling strategies, but selection of the individual respondents was purposive as appropriate. There may be a chance to select non-informative respondents. This type of problem was resolved by the selection of key respondents. Among the study subjects, there were four significant groups involved with medical waste related activities. Consequently, in group selection, the aim was to match the same working activities. But the ratio of the individuals in each group was not followed. There may be a chance to mismatch the selection of respondents. In its most elemental application, differing populations among the study subjects can lead to problems of detection and interpretation. This was strictly considered and care was taken in choosing populations to assess the occupational stress by adopting multi-layer approach.

Survey data (both quantitative and qualitative) are not more accurate than quantitative laboratory-based data, since they are not free from bias and more open to reflecting respondents' perceptions. However, the problem was solved and discussed through multiple sources of data collection procedures.

The quality of results depends on the frequently unknown quality of consistently collected data. Collected data may need lengthy editing prior to analyses. The methodology may not be too significant for the analysis of occupational stress with small numbers of cases. However, the sample frame of the self-reported disease assessment was statistically significant.

There are a number of issues which could potentially limit participation or introduce bias to the results. The first of these may arise because HCEs were initially concerned that any data collected as part of this study might be used against the HCE to assess official penalties or to jeopardise the image of HCE. To address this concern, a series of meetings was organized with appropriate authorities from the HCE and with the selected respondents to reassure them that confidentiality would be strictly observed, and that the data was to be collected only for academic research purposes. Following this process, HCEs generally agreed to participate; a substitution procedure (as described in Patwary et al. ${ }^{[45]}$ was adopted for those HCEs (7) for which consent could not be obtained. Another constraint arose because many 
operatives were concerned that participation would lead to prosecution for involvement with illegal activities, or that their identity would be published. Some initially hid to avoid contact with the investigators. This was addressed by adopting an extended, informal, dialogue approach by which the researcher attempted to establish contact and develop trust, allowing the purpose and conduct of the survey to be explained.

\section{Conclusion}

Job-related stress has previously been linked to vulnerability to drug addiction ${ }^{[38,69,70]}$. However, multiple social and psychological factors, in addition to biological susceptibilities, also contribute to tendencies to develop drug addictions. In the case of medical waste workers in Bangladesh, social marginalization and the horrific work conditions, combined with a fatalistic world view, likely underlie the extremely high percentage of individuals reporting drug abuse in this population. Efforts towards prevention and intervention in this community must take into account these unique socio-cultural constraints.

\section{Acknowledgements}

First author acknowledge financial support from Charles Wallace Bangladesh Trust, the Charles Wallace Trust UK, The Gilchrist Trust, The S.A. Ziauddin Trust, Mountbatten Memorial Grant, The Hammond Trust, The Leche Trust and The Churches Commission Overseas Trust for data collection in Bangladesh. Also thank to Linda Chambers, School Manager, School of Science and Engineering, Teesside University UK, for her continued financial support. We also thank Obaida Akhter, Officer, BASIC Bank Ltd. Bangladesh for her helpful comments as an independent verifier for qualitative data translation and critical reading of the manuscript.

\section{References}

[1] Volkow ND and Li T. Drug addiction: the neurobiology of behaviour gone awry. Nature Reviews Neuroscience. 2004 ; 5: 963-970. PMid:15550951 http://dx.doi.org/10.1038/nrn1539

[2] Goodman A. Neurobiology of addiction: An integrative review. Biochemical Pharmacology. 2008; 75: 266-322. PMid:17764663 http://dx.doi.org/10.1016/j.bcp.2007.07.030

[3] Koob G F and Volkow N D. Neurocircuitry of addiction. Neuropsychopharmacology REVIEWS. 2010; 35: $217-238$. PMid:19710631 http://dx.doi.org/10.1038/npp.2009.110

[4] Hawkins J D, Graham J W, Maguin E, Abbott R D, Hill KG, Catalano R F. Exploring the effects of age of alcohol use initiation and psychosocial risk factors on subsequent alcohol misuse. Journal of Studies on Alcohol. 1997; 58: 280-290. PMid:9130220

[5] Zucker R A. Alcohol use and the alcohol use disorders: a developmental biopsychosocial systems formulation covering the life course. In: Cicchetti, D., Cohen, D.J. (Eds.), Developmental Psychopathology. Vol. 3: Risk, Disorder, and Adaptatio, 2nd ed. John Wiley \& Sons. 2006. Hoboken, NJ, pp. 620-656.

[6] Koob G F and Volkow N D. Neurocircuitry of addiction. Neuropsychopharmacology. 2010; 35(1): 217-38. PMid:19710631 http://dx.doi.org/10.1038/npp.2009.110

[7] Clark D and Sayette M. Anxiety and the development of alcoholism. American J Addict. 1993; 2: 59-76. http://dx.doi.org/10.3109/10550499309115943

[8] Swendsen J D, Tennen H, Carney M A, Affleck G, Willard A, Hromi A. Mood and alcohol consumption: an experience sampling test of the self-medication hypothesis. Journal of Abnormal Psychology. 2000; 109: 198-204. PMid:10895557 http://dx.doi.org/10.1037/0021-843X.109.2.198

[9] Khantzian E J and Albanese M J. Understanding Addiction as Self Medication: Finding Hope Behind the Pain. 2008. Rowman \& Littlefield, Lanham, MD.

[10] Margolis B K and Kroes WH. Occupational stress and strain. In:McLean, A. (Ed.), Occupational Stress. 1974. Charles C Thomas, Springfield, IL.

[11] Estryn-Behar M, Kaminski M, Peigne E. Stress at work and mental health status among female hospital workers. British Journal of Industrial Medicine. 1990; 47: 20-28. PMid:2310704

[12] Vasse RM, Nijhuis F J N, Kok G. Associations between work stress, alcohol consumption and sickness absence. Addiction. 1998; 93: 231-241. PMid:9624724 http://dx.doi.org/10.1046/j.1360-0443.1998.9322317.x

Published by Sciedu Press 
[13] Gottesman I.I and Gould TD. The endophenotype concept in psychiatry: etymology and strategic intentions. American Journal of Psychiatry. 2003; 160: 636-645. http://dx.doi.org/10.1176/appi.ajp.160.4.636

[14] Cosper R. Drinking as conformity: A critique of sociological literature on occupational differences in drinking. Journal of Studies on Alcohol. 1979; 40: 868-891. PMid:513778

[15] Parker D A and Wolz M W. Alcohol problems and the availability of alcohol. Alcohol and Clinical Experimental Research. 1979; 3: 309-312. http://dx.doi.org/10.1111/j.1530-0277.1979.tb05328.x

[16] Fennell M L, Rodin M B, Kantor G K. Problems in the work setting, drinking, and reasons for drinking. Social Forces. 1981; 60(l): 114-132.

[17] Casswell S, \& Gordon A. Drinking and occupational status of New Zealand men. Journal of Studies on Alcohol. 1984 ; 45: $144-148$. PMid:6727374

[18] Harris M S and Femel M L. A multivariate model of job stress and alcohol consumption. Sociological Quarterly. 1988 ; $29: 391-406$. http://dx.doi.org/10.1111/j.1533-8525.1988.tb01260.x

[19] Cooper M L, Russell M, Frome M R. Work stress and alcohol effects: A test of stress-induced drinking. Journal of Health and Social Behavior. 1990; 31: 260-276. PMid:2133480 http://dx.doi.org/10.2307/2136891

[20] Gleason P M, Veum J R, Pergamit M R. Drug and alcohol use at work: A survey of young workers. Monthly Labor Review, 1991; $\mathrm{J} / 4(8): 3-7$.

[21] Seeman M and Seeman A Z. Life strains, alienation, and drinking behaviour. Alcoholism: Clinical and Experimental Research. 1992; 16 (2): 199-205. http://dx.doi.org/10.1111/j.1530-0277.1992.tb01364.x

[22] Chen MJ, \& Cunradi C. Job stress, burnout and substance use among urban transit operators: The potential mediating role of coping behaviour. Work \& Stress. 2008; 22(4): 327-341. http://dx.doi.org/10.1080/02678370802573992

[23] Frone M R. Are work stressors related to employee substance use? The importance of temporal context in assessments of alcohol and illicit drug use. Journal of Applied Psychology. 2008; 93(1): 199-206. PMid:18211145 http://dx.doi.org/10.1037/0021-9010.93.1.199

[24] Bonn D, \& Bonn J. Work-related stress: Can it be a thing of the past? Lancet. 2000; 355: 124. http://dx.doi.org/10.1016/S0140-6736(05)72040-7

[25] Karasek R A, Theorell T. Healthy Work: Stress, Productivity, and the Reconstruction of Working Life. 1990. Basic Books, New York.

[26] Bourbonnais R, Brisson C, Moisan J, Vezina M. Job strain and psychological distress in white-collar workers. Scand. J. Work Environ. Health. 1996; 22: 139-145. PMid:8738893 http://dx.doi.org/10.5271/sjweh.122

[27] Schnall P L, Landsbergis P A, Baker D. Job strain and cardiovascular disease. Annu. Rev. Public Health. 1994; $15: 381-411$. PMid:8054091 http://dx.doi.org/10.1146/annurev.pu.15.050194.002121

[28] Bongers PM, De Winter CR, Kompier MAJ, Hildebrandt VH. Psychosocial factors at work and musculoskeletal disease. Scand. J. Work Environ. Health. 1993; 19: 297-312. PMid:8296178 http://dx.doi.org/10.5271/sjweh.1470

[29] Klonoff-Cohen H S, Cross J L, Pieper CF. Job stress and pre-eclampsia. Epidemiology. 1996; 7: 245-249. PMid:8728436 http://dx.doi.org/10.1097/00001648-199605000-00005

[30] Crum RM, Helzer JE, Anthony JC. Level of education and alcohol abuse and dependence in adulthood: a further inquiry. Am. J. Public Health. 1993; 83: 830-837. http://dx.doi.org/10.2105/AJPH.83.6.830

[31] Droomers CTM, Schrijvers K, Stronks D, Van de Mheen, Mackenbach JP. Educational differences in excessive alcohol consumption: the role of psychosocial and material stressors. Prevention Medicine. 1999; 29: 1-10. PMid:10419792 http://dx.doi.org/10.1006/pmed.1999.0496

[32] Khan S, Murray R P, Barnes G E. A structural equation model of the effect of poverty and unemployment on alcohol abuse. Addictive Behaviour. 2002; 27: 405-423. http://dx.doi.org/10.1016/S0306-4603(01)00181-2

[33] Van Manen, M. Phenomenology of Practice, Phenomenology and Practice. 2007; 1 (1): 11-30.

[34] Brysiewicz P. The lived experience of working in a mortuary. Accident and Emergency Nursing. 2007; 15: 88-93. PMid:17451956 http://dx.doi.org/10.1016/j.aaen.2007.03.001

[35] Patwary MA, O’Hare WT, Hassan MM, Elahi KM, Sarker MH. Domes and the Dead: an example of extreme fatalism among mortuary workers in Bangladesh. Kaleidoscope. 2010; 4 (1): 10-18.

[36] Patwary MA, O’Hare WT, Sarker. Occupational accident: an example of fatalistic beliefs among medical waste workers in Bangladesh. Safety Science. 2012a; 50: 76-82. http://dx.doi.org/10.1016/j.ssci.2011.07.004

[37] Patwary MA, O’Hare WT, Karim SA, Sarker MH. The motivations of young people moving into medical waste scavenging as a street career. Journal of Youth Studies. 2012b; 15(5): 591-604. http://dx.doi.org/10.1080/13676261.2012.665441

[38] Patwary M A and Sarker M H. Quantitative assessment of mortuary waste: occupational safety and environmental health. Journal of Hospital Administration. 2012; 2 (1): 49-60. http://dx.doi.org/10.5430/jha.v1n1p49 
[39] Patwary MA, O’Hare WT, Sarker MH. Assessment of occupational and environmental safety associated with medical waste disposal in developing countries: a qualitative approach. Safety Science. 2011a; 49 (8-9): 1200-1207.

http://dx.doi.org/10.1016/j.ssci.2011.04.001

[40] Patwary MA, O’Hare WT, Sarker. An illicit economy: scavenging and recycling of medical waste. Journal of Environmental Management. 2011b; 92 (11): 2900-2906. PMid:21820235 http://dx.doi.org/10.1016/j.jenvman.2011.06.051

[41] Zene C. Myth, identity and belonging: The Rishi of Bengal/Bangladesh. Religion. 2007; 37: 257-281. http://dx.doi.org/10.1016/j.religion.2007.10.002

[42] Cochran WG. Sampling Techniques, 3rd Ed, John wiley and Sons. 1977; 75.

[43] Barnett Vic. Sample survey: principles and methods, Third Edition, Oxford University Press, 2002. ISBN10: 0340763981.

[44] Islam M N. An Introduction to Sampling Methods, Theory and Applications, Book World. 2005. ISBN 984-32-1976-7.

[45] Patwary MA, O’Hare WT, Street G, Elahi KM, Hossain SS, Sarker MH. Quantitative assessment of medical waste generation in the capital city of Bangladesh. Waste Management. 2009a; 29 (8): 2392-2397. PMid:19375297 http://dx.doi.org/10.1016/j.wasman.2009.03.021

[46] Patwary MA, O’Hare WT, Street G, Elahi KM, Hossain SS, Sarker MH. Health and safety perspective on medical waste management in a developing country: A case study of Dhaka city. In Nabhani, F. (ed) Proceedings of the 19th international FAIM conference. Gemini International Limited 2009b: pp.282-290. ISBN: 978-0-9562303-2-4.

[47] Thompson S K and Frank O. Model-based estimation with linktracing sampling designs. Survey Methodology. 2000; $26:$ 87-98.

[48] Clements K, Gleghorn A, Garcia D, Katz M, Marx R. A Risk Profile of Street Youth in Northern California: Implications for Gender-Specific Human Immunodeficiency Virus Prevention. Journal of Adolescent Health. 1997; 20: 343-353. http://dx.doi.org/10.1016/S1054-139X(97)00033-5

[49] Thompson SK and Collins LM. Adaptive sampling in research on risk-related behaviours. Drug and Alcohol Dependence. 2002; 68: 57-67. http://dx.doi.org/10.1016/S0376-8716(02)00215-6

[50] Chaudhuri A, Bose M, Ghosh J K. An application of adaptive sampling to estimate highly localized population segments. Journal of Statistical Planning and Inference. 2004; 121: 175-189. http://dx.doi.org/10.1016/S0378-3758(03)00117-4

[51] Jorgensen D.L. Practical Observation: a methodology for human studies. 1989. London: Sage.

[52] Kock N. The three threats of action research: a discussion of methodological antidotes in the context of an information systems study. Decision Support Systems. 1996; 37: 265-286. http://dx.doi.org/10.1016/S0167-9236(03)00022-8

[53] Choi E, Hall P, Rousson V. Data sharpening methods for bias reduction in nonparametric regression. The Annals of Statistics. 2000; 28(5): 1339-1355.

[54] Van Manen M. Researching Lived Experience: Human Science for an Action Sensitive Pedagogy. 1990. Albany, NY: State University of New York Press.

[55] Van Manen M. Researching Lived Experience. Human Science for an Action ensitive Pedagogy. 2003. Ontario: Althouse Press.

[56] Palmer R. Hermeneutics: Interpretation Theory in Schleiermacher, Dilthey, Heidegger and Gadamer. 1969. Northwestern University Press, Evanston.

[57] Urmson J O \& Jonathan R. The Concise Encyclopaedia of Western Philosophy. 2005. Routledge: New York. PMid:15760388

[58] Glaser B G \& Strauss A. Discovery of Grounded Theory. Strategies for Qualitative Research. 1967. Sociology Press.

[59] Statistical Services Centre, 2001. Approaches to the analysis of survey data. University of Reading, Biometrics Advisory and Support Service to DFID.

[60] Nielsen E M, Breum N O, Nielsen B H, Wurtz H, Poulsen O M, Midtgaard U. Bioaerosol exposure in waste collection: A comparative study of the significance of collection equipment, type of waste and seasonal variation. Ann. Occupational. Hygiene. 1997; 41: 325-344.

[61] Blum K, Noble EP, Sheridan PJ, Montgomery A, Ritchie T, Jagadeeswaran P, Nogami H, Briggs AH, Cohn JB. Allelic association of human dopamine D2 receptor gene in alcoholism. JAMA. 1990; 263: 2055-2060. PMid:1969501 http://dx.doi.org/10.1001/jama.1990.03440150063027

[62] Limosin F, Loze J Y, Dubertret C, Gouya L, Ades J, Rouillon F, Gorwood P. Impulsiveness as the intermediate link between the dopamine receptor D2 gene and alcohol dependence. Psychiatric Genetics. 2003; 13: 127-129. PMid:12782972 http://dx.doi.org/10.1097/01.ypg.0000066963.66429.00

[63] Hopfer C J, Timberlake D, Haberstick B C, Lessem J M, Ehringer M A, Smolen A, Hewitt J K. Genetic influences on quantity of alcohol consumed by adolescents and young adults. Drug and Alcohol Dependence. 2005; 78: 187-193. PMid:15845322 http://dx.doi.org/10.1016/j.drugalcdep.2004.11.003

[64] Ross S and Peselow E. The Neurobiology of Addictive Disorders. Clinical Neuropharmacology. 2009; 32(5): $269-276$. PMid:19834992 http://dx.doi.org/10.1097/WNF.0b013e3181a9163c 
[65] Dishion TJ and Kavanagh K. Intervening in Adolescent Problem Behavior: A Family-centered Approach. 2003. Guilford Press, New York.

[66] Garden P. Rising from the dead: delimiting stigma in the Australian funeral industry. Health Sociology Review. 2001 ; 10 : $79-87$. http://dx.doi.org/10.5172/hesr.2001.10.2.79

[67] Bergman M E and Katherine M C. Ex' Marks a Spot: The Stickness of Dirty Work and Other Removed Stigmas. Journal of Occupational Health Psychology. 2007; 12 (3): 251-265. PMid:17638491 http://dx.doi.org/10.1037/1076-8998.12.3.251

[68] McCarroll J, Ursano R, Wright KM, Fullerton C S. Handling bodies after violent death: strategies for coping. American Journal of Orthopsychiatry. 1993; 63 (2): 209-214. PMid:8484426 http://dx.doi.org/10.1037/h0079438

[69] Chaturvedi, H.K. and Mahanta, J. Sociocultural diversity and substance use pattern in Arunachal Pradesh, India. Drug Alcohol Dependence. 2004; 74: 97-104. PMid:15072813 http://dx.doi.org/10.1016/j.drugalcdep.2003.12.003

[70] Saldanha, I.M. On drinking and “drunkenness”: history of liquor in colonial India”. Economic Policy Weekly. $1995 ; 23: 23-31$. 